\title{
Improved Efficiency of Graphene/Si Heterojunction Solar Cells by Optimizing Hydrocarbon Feed Rate
}

\author{
Zexia Zhang, ${ }^{1}$ Tongxiang Cui, ${ }^{1}$ Ruitao Lv, ${ }^{1}$ Hongwei Zhu, ${ }^{1,2}$ Kunlin Wang, \\ Dehai $\mathrm{Wu},{ }^{1}$ and Feiyu Kang ${ }^{1,3}$ \\ ${ }^{1}$ Key Laboratory of Advanced Materials (MOE), School of Materials Science and Engineering, Tsinghua University, \\ Beijing 100084, China \\ ${ }^{2}$ Center for Nano and Micro Mechanics, Tsinghua University, Beijing 100084, China \\ ${ }^{3}$ Graduate School at Shenzhen, Tsinghua University, Shenzhen, Guangdong 518055, China
}

Correspondence should be addressed to Ruitao Lv; lvruitao@tsinghua.edu.cn and Feiyu Kang; fykang@tsinghua.edu.cn

Received 7 March 2014; Accepted 24 April 2014; Published 15 June 2014

Academic Editor: Jinlong Jiang

Copyright (c) 2014 Zexia Zhang et al. This is an open access article distributed under the Creative Commons Attribution License, which permits unrestricted use, distribution, and reproduction in any medium, provided the original work is properly cited.

\begin{abstract}
Four different graphene films were synthesized via chemical vapor deposition by using acetonitrile with feed rates of $0.01,0.02$, 0.04 , and $0.06 \mathrm{~mL} / \mathrm{min}$. Heterojunction solar cells were assembled by transferring as-synthesized graphene films onto $n$-Si. Solar cells based on graphene samples produced at $0.01,0.02,0.04$, and $0.06 \mathrm{~mL} / \mathrm{min}$ demonstrate power conversion efficiencies of $2.26 \%, 2.10 \%, 1.02 \%$, and $0.94 \%$, respectively. When $\mathrm{HNO}_{3}$ was used to dope the graphene films, the corresponding photovoltaic efficiencies were increased to $4.98 \%, 4.19 \%, 2.04 \%$, and $1.74 \%$, respectively. Mechanism for the improved efficiency of graphene/Si heterojunction solar cells was also investigated.
\end{abstract}

\section{Introduction}

The application of graphene in photovoltaics has attracted tremendous research interest due to its unique twodimensional structure [1,2], high light transmittance [3], and excellent carrier mobility $[4,5]$. Indium tin oxide (ITO) is a commercialized transparent electrode for solar cells [6], but ITO suffers from many drawbacks, such as high cost, limited resource of indium and brittle textures [7]. It was shown that graphene could be a possible candidate for replacing ITO in organic solar cells $[3,8]$. Furthermore, graphene also shows the potential to replace platinum $(\mathrm{Pt})$ in dye-sensitized solar cells (DSSCs) $[9,10]$. As is known, the role of Pt in DSSCs is to catalyze the reduction of $\mathrm{I}_{3}{ }^{-}$to $\mathrm{I}^{-}$at counter electrode [11]. However, Pt is very costly and has limited supply on the earth. Replacement of Pt by other inexpensive and abundant materials is also very important. Pt-free counter electrode was developed recently by using graphene supported nickel nanoparticles as catalyst, and the corresponding solar cell efficiency had an increase of 10\% than that of Pt-based DSSCs [11]. In addition, graphene could also be used as an active layer for $p$ - $n$ junction and participate in the photo-carrier generation process [12]. Schottky junction solar cells had been assembled by transferring graphene onto various semiconducting substrates, such as Si [12], CdS [13], and CdSe [14]. A recent work showed that the initial efficiency of graphene/Si $(\mathrm{G} / \mathrm{Si})$ solar cell reached $1.9 \%$, and it could be further improved to $8.6 \%$ by bis(trifluoromethanesulfonyl)imide $\left[\left(\left(\mathrm{CF}_{3} \mathrm{SO}_{2}\right)_{2}\right) \mathrm{NH}\right]$ doping [15].

Due to the simple design and efficient photovoltaic conversion, G/Si Schottky junction solar cells have attracted increasing interests and exciting progress has been achieved recently [16-18]. However, there are still many fundamental questions which need to be addressed. In particular, the influence of many factors on the performance of G/Si solar cells is still under investigation, such as chemical doping of graphene films $[15,19,20]$, the environment gas flow [21, 22], and the thickness of graphene sheets [23]. Besides that, feed rate of hydrocarbon precursors is also an important factor in graphene synthesis $[24,25]$. For example, our previous work has demonstrated that graphene and carbon films could be selectively synthesized by adjusting the feed rate of 
acetonitrile [24]. Many impurities and agglomerates could be observed on graphene surface if the feed rate of hydrocarbon precursor was not optimized $[25,26]$. However, the effect of hydrocarbon precursor feed rate on the photovoltaic performance of graphene has been rarely investigated.

In this work, four graphene films were obtained at different acetonitrile feed rates $(0.01,0.02,0.04$, and $0.06 \mathrm{~mL} / \mathrm{min})$. $\mathrm{G} / \mathrm{Si}$ heterojunction solar cells based on these graphene films demonstrate efficiencies of $2.26 \%, 2.10 \%, 1.02 \%$, and $0.94 \%$, respectively. Moreover, the respective efficiencies could be enhanced to $4.98 \%, 4.19 \%, 2.04 \%$, and $1.74 \%$ upon $\mathrm{HNO}_{3}$ treatment. It is clearly shown that high feed rate of acetonitrile plays a negative role in the photovoltaic performance of graphene, and the reason for that is discussed in detail.

\section{Experiment}

2.1. Synthesis of Graphene. The experimental setup and procedure are described in detail elsewhere [24]. $\mathrm{Cu}$ foil is used as substrate, located in the middle of the quartz tube reactor, and gradually heated up to $900^{\circ} \mathrm{C}$ in an $\operatorname{Ar}(300 \mathrm{~mL} / \mathrm{min})$ flow. $\mathrm{H}_{2}$ is introduced into the reactor as the temperature reaches $900^{\circ} \mathrm{C}$, and the $\mathrm{Cu}$ substrate is annealed at $900^{\circ} \mathrm{C}$ for $1 \mathrm{~h}$ to homogenize the crystal grain. After that, the temperature is raised to $1000^{\circ} \mathrm{C}$ at a rate of $10^{\circ} \mathrm{C} / \mathrm{min}$. Then, acetonitrile is fed into the reactor at a given rate $(0.01,0.02,0.04$, or $0.06 \mathrm{~mL} / \mathrm{min})$ in an $\mathrm{Ar}(2000 \mathrm{~mL} / \mathrm{min}) / \mathrm{H}_{2}(30 \mathrm{~mL} / \mathrm{min})$ flow for $5 \mathrm{~min}$. When the feeding of acetonitrile is cut off, the $\mathrm{Cu}$ foil is quickly moved to the low-temperature region of the reactor to ensure fast-cooling rate.

2.2. Transfer of Graphene. Samples of as-synthesized graphene on $\mathrm{Cu}$ foil were cut into pieces with sizes of $\sim 6 \mathrm{~mm} \times$ $6 \mathrm{~mm}$ and then etched in a mixed solution of $\mathrm{FeCl}_{3} / \mathrm{HCl}$. After the $\mathrm{Cu}$ was completely etched away, the graphene films were floating on the surface of $\mathrm{FeCl}_{3} / \mathrm{HCl}$ solution. Then, the graphene films were rinsed with deionized water for several times and transferred onto arbitrary substrate for characterization and device fabrication.

2.3. Characterization of Graphene. Optical transmission spectra of graphene films were collected by a UV-2450 UV/vis optical spectrometer. The sheet resistance of the graphene films was measured using a four-probe resistivity test system. The morphologies of graphene samples were characterized by scanning electron microscope (SEM, JSM-6460 LV) and transmission electron microscope (TEM, JEOL-2010).

2.4. Solar Cell Device Assembly and Evaluation. The details of the solar cell assembly can be found in our previous work [27]. In a typical process, as-synthesized graphene film (with $\mathrm{Cu}$ substrate) was cut into pieces and then etched in a mixed solution of $\mathrm{FeCl}_{3} / \mathrm{HCl}$. After 2 3 hours, the $\mathrm{Cu}$ substrate could be completely etched away at room temperature. The detached graphene film will float on the surface of the $\mathrm{FeCl}_{3} / \mathrm{HCl}$ solution. After being rinsed with deionized water for several times, the graphene film was transferred onto $n$-type Si wafer (with a square window of $3 \mathrm{~mm} \times 3 \mathrm{~mm}$

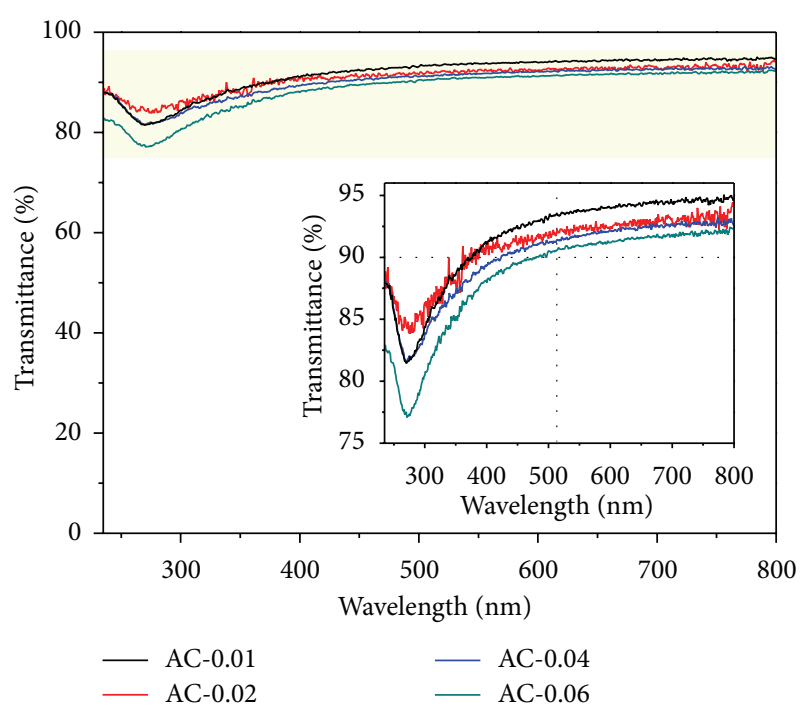

(a)

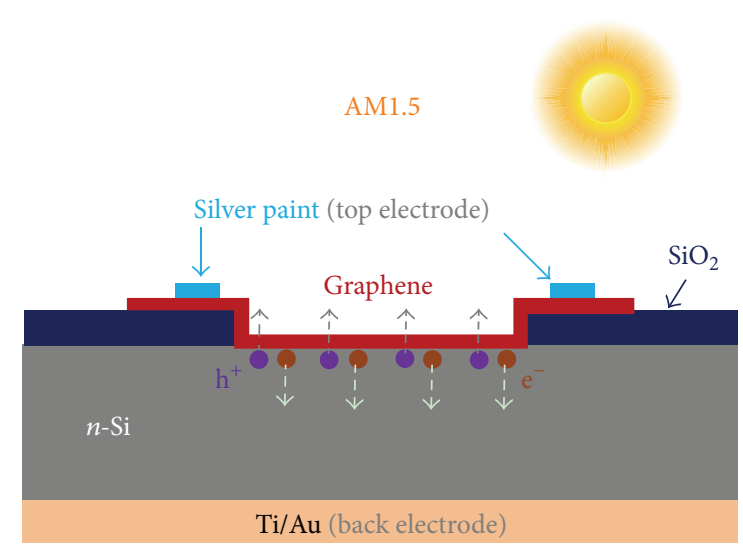

(b)

Figure 1: (a) Optical transmission spectra of different graphene samples. Inset is the enlarged spectra of the parts highlighted with light yellow color. (b) A schematic diagram of the solar cell device configuration. In this kind of device, photo-generated holes $\left(\mathrm{h}^{+}\right)$and electrons $\left(\mathrm{e}^{-}\right)$are driven by the built-in electric field into graphene and $n$-Si, respectively.

surrounded by insulating $\mathrm{SiO}_{2}$ ) to construct a heterojunction solar cell. Ag paste and $\mathrm{Ti} / \mathrm{Au}$ were used as top and back electrodes, respectively. The assembled solar cell devices were evaluated with a solar simulator (Newport, at AM 1.5, $100 \mathrm{~mW} / \mathrm{cm}^{2}$ ) and a Keithley 2400 SourceMeter.

\section{Results and Discussion}

The graphene samples produced at acetonitrile feed rate of $0.01,0.02,0.04$, and $0.06 \mathrm{~mL} / \mathrm{min}$ were labelled as AC-0.01, AC-0.02, AC-0.04, and AC-0.06, respectively. The transmission spectra of the graphene samples produced at different feed rates were shown in Figure 1(a). All the samples show high transparency in the UV-Vis range with transmittances 


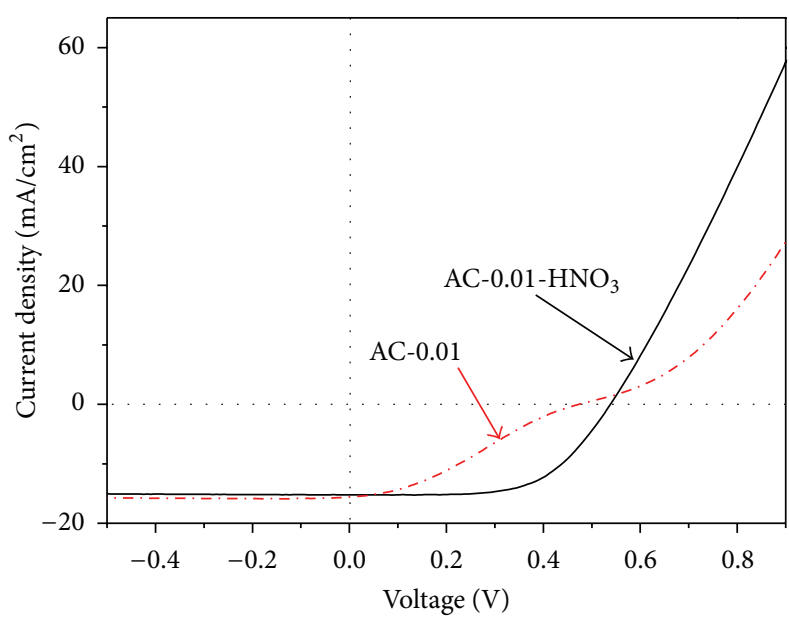

(a)

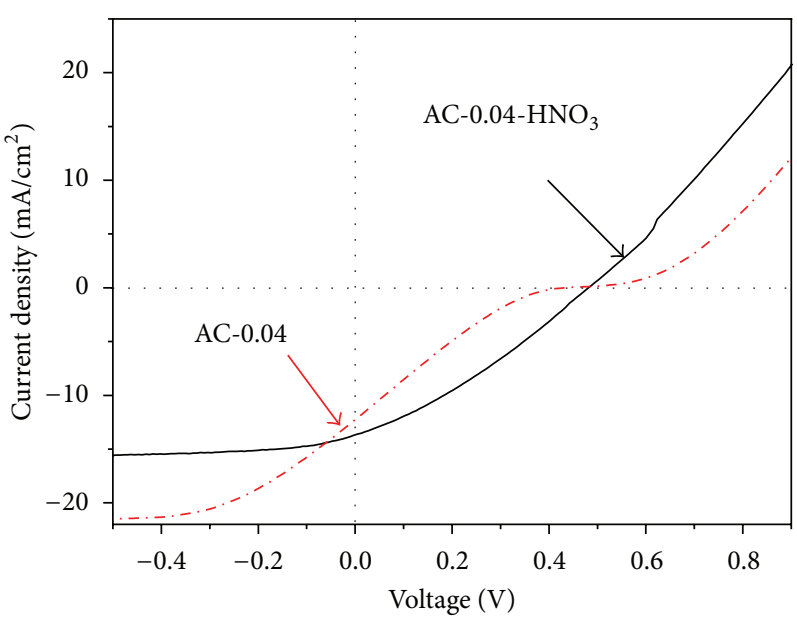

(c)

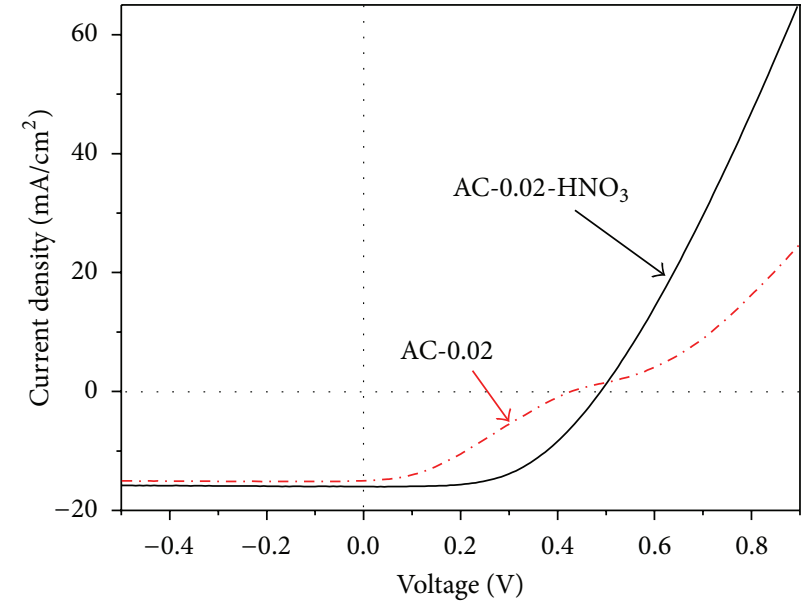

(b)

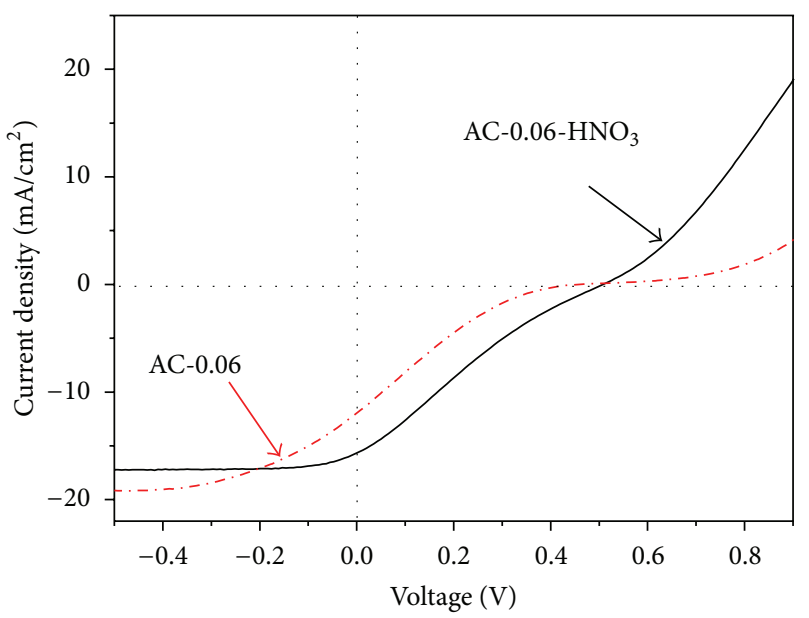

(d)

Figure 2: Light current density-voltage curves of solar cells based on different graphene samples before (red lines) and after $\mathrm{HNO}_{3}(\mathrm{black}$ lines) treatment. (a) AC-0.01, (b) AC-0.02, (c) AC-0.04, and (d) AC-0.06.

up to $90 \%$ at $550 \mathrm{~nm}$ wavelength. The sheet resistance of $\mathrm{AC}$ $0.01, \mathrm{AC}-0.02$, AC-0.04, and AC-0.06 is $1080,1135,1353$, and $1415 \Omega /$ sq, respectively. Raman spectra and high resolution TEM image (see Figure S1 in Supplementary Material available online at http://dx.doi.org/10.1155/2014/359305) were used to identify the layers of these samples, and the higher intensity of 2D-band than that of G-band in Figure S1(a) proves the graphene films are mainly few-layer ones (about less than 3 layer), which is also confirmed by HRTEM image (Figure S1(b)). The graphene samples are highly transparent and conductive, making them appealing in G/Si heterojunction solar cell applications.

G/Si heterojunction solar cells were assembled by transferring as-synthesized graphene films onto $n$-type $\mathrm{Si}$. A schematic diagram of the G/Si heterojunction solar cell is shown in Figure 1(b). High purity silver paint is used to form ohmic contacts between graphene and silver wire, which is used as an electrode for electrical measurements. In this device, graphene films can act not only as the active part of Schottky junction, but also as the transparent anode electrode. A space-charge region accompanied by a builtin electric field is formed at the interface of graphene and $n$-Si because of their work function difference. The photogenerated holes $\left(\mathrm{h}^{+}\right)$and electrons $\left(\mathrm{e}^{-}\right)$are driven by the built-in electric field into the graphene and $n$-Si, respectively.

The current density $(J)$ versus voltage $(V)$ curves of solar cells based on the graphene films produced at different acetonitrile feed rates are shown in Figure 2. The corresponding photovoltaic parameters, such as short circuit current density $\left(J_{\mathrm{sc}}\right)$, open circuit voltage $\left(V_{\mathrm{oc}}\right)$, filling factor $(\mathrm{FF})$, and power conversion efficiency $(\eta)$, are listed in Table 1 . As shown in Table 1, solar cells based on AC-0.01, AC-0.02, AC-0.04, and AC-0.06 demonstrate $\eta$ of $2.26 \%, 2.10 \%, 1.02 \%$, and $0.94 \%$, respectively. The $\eta$ of solar cells based on AC-0.01 and AC-0.02 shows comparable photovoltaic performance with previous report work about G/Si solar cells $[12,26$, 28]. However, the efficiencies are still far from practical applications. $\mathrm{HNO}_{3}$ was used to modify the graphene films and to enhance the photovoltaic performance of assembled solar cells. The assembled G/Si cells were placed above a vial 


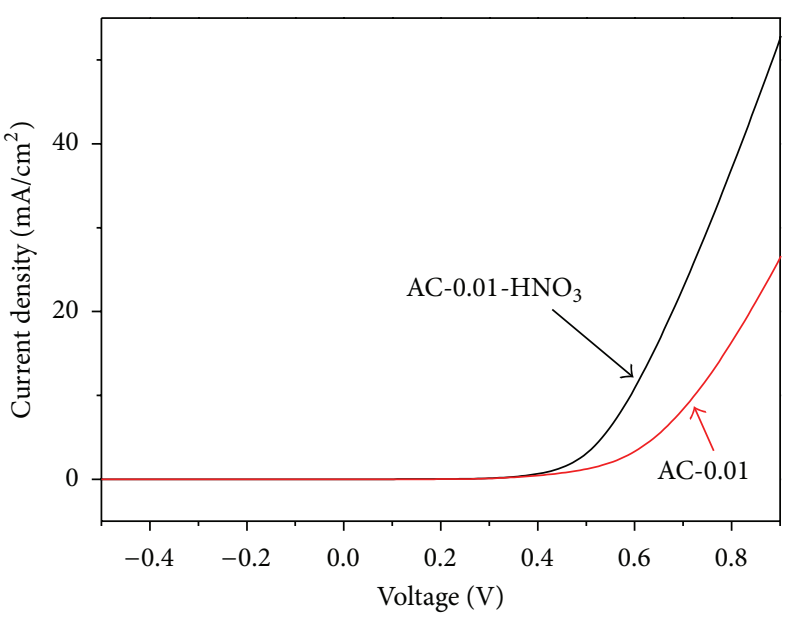

(a)

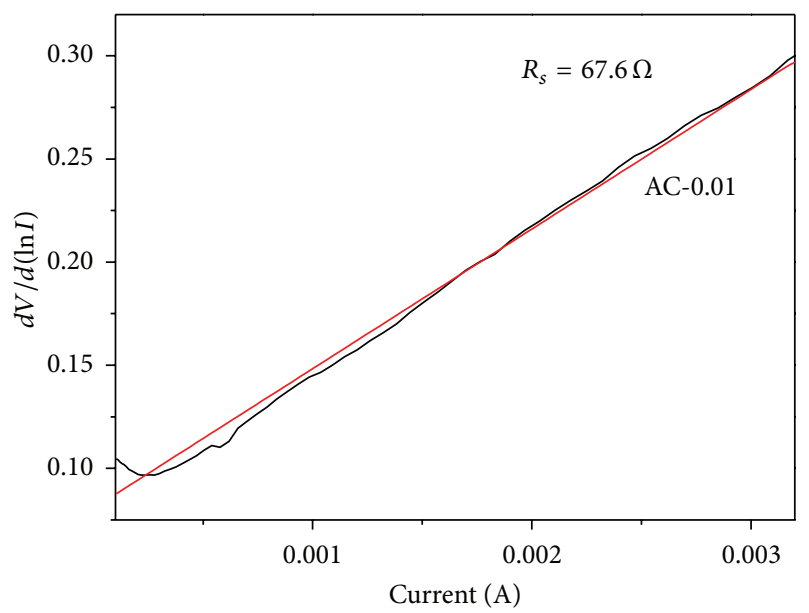

(c)

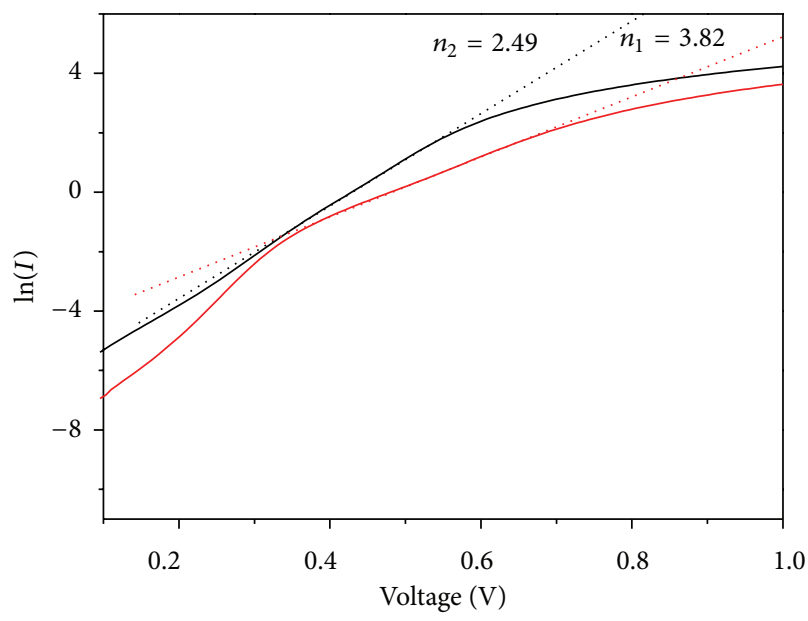

(b)

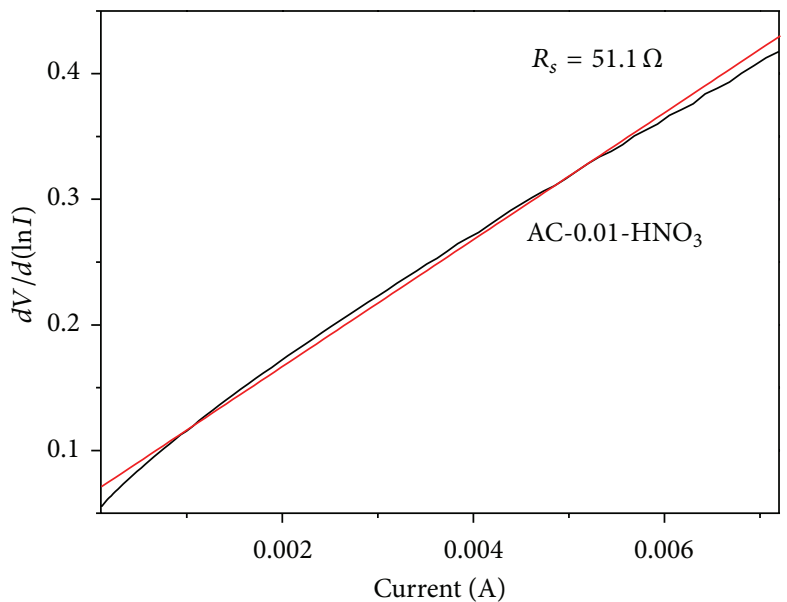

(d)

Figure 3: Mechanism for the efficiency improvement by $\mathrm{HNO}_{3}$ treatment. (a) Dark current density-voltage curves of solar cells based on AC- 0.01 before (red line) and after $\mathrm{HNO}_{3}$ (black line) treatment. (b) Plots of $\ln (I)$ versus voltage showing diode ideality factors before $\left(n_{1}\right)$ and after $\left(n_{2}\right) \mathrm{HNO}_{3}$ treatment. ((c), (d)) Linear fit of $\mathrm{d} V / \mathrm{d}(\ln I)$ versus $I$ shows the $R_{\mathrm{s}}$ of the AC- 0.01 solar cell before and after $\mathrm{HNO}_{3}$ treatment: (c) before $\mathrm{HNO}_{3}$ treatment and (d) after $\mathrm{HNO}_{3}$ treatment.

containing fuming $\mathrm{HNO}_{3}$ (65 wt\%). The treatment time was fixed at $1 \mathrm{~min}$, in case of corrosion of silver and underlying $\mathrm{Si}$ at longer time [19]. Upon $\mathrm{HNO}_{3}$ treatment, the efficiencies of solar cells based on AC-0.01, AC-0.02, AC-0.04, and AC0.06 could be increased to $4.98 \%, 4.19 \%, 2.04 \%$, and $1.74 \%$, respectively. That means the efficiencies of the G/Si solar cells almost doubled upon $\mathrm{HNO}_{3}$ treatment, which accords with previous reported works $[19,28]$. The corresponding photovoltaic parameters after $\mathrm{HNO}_{3}$ treatment are also listed in Table 1. The reasons why the efficiencies of G/Si solar cells could be enhanced by $\mathrm{HNO}_{3}$ treatment are discussed as follows. Firstly, $\mathrm{HNO}_{3}$ treatment could increase the work function of graphene film by $p$-doping [19]. As it was demonstrated in our previous work, increasing the work function of graphene is beneficial for a larger $V_{\text {oc }}$ of the G/Si Schottky junction $[19,29]$. It can be seen from Table 1 , the $V_{\text {oc }}$ of all the solar cells has an increase of $\sim 55 \mathrm{mV}$ after $\mathrm{HNO}_{3}$ treatment. Secondly, the conductivity of the graphene films could also be increased by $\mathrm{HNO}_{3}$ treatment because of $p$ doping $[19,30]$. The sheet resistance of AC- 0.01, AC- 0.02 , AC0.04 , and AC-0.06 reduced from 1080 to $581 \Omega /$ sq, from 1135 to $598 \Omega /$ sq, from 1353 to $707 \Omega /$ sq, and from 1415 to $744 \Omega /$ sq, respectively. The enhanced conductivity of graphene film is good for the increase of $J_{s c}$ and reducing the internal resistance $\left(R_{s}\right)$ of the solar cell. The increase of $J_{\mathrm{sc}}$ could be observed in solar cells based on AC-0.02, AC-0.04, and AC0.06 (Table 1). Interestingly, there is a slight decrease of $J_{\mathrm{sc}}$ in AC- 0.01 solar cell (from 15.57 to $15.23 \mathrm{~mA} / \mathrm{cm}^{2}$ ), which might result from the slight corrosion of silver paint or silver wire. Thirdly, $\mathrm{HNO}_{3}$ treatment could reduce the $R_{s}$ of the solar cell and improve the quality of the G/Si Schottky junction, resulting in larger FF.

Dark current density-voltage curves of the AC-0.01 solar cell before (black curve) and after (red curve) $\mathrm{HNO}_{3}$ treatment are shown in Figure 3(a). The dark curves exhibit rectifying characteristics, and we can qualitatively see from 


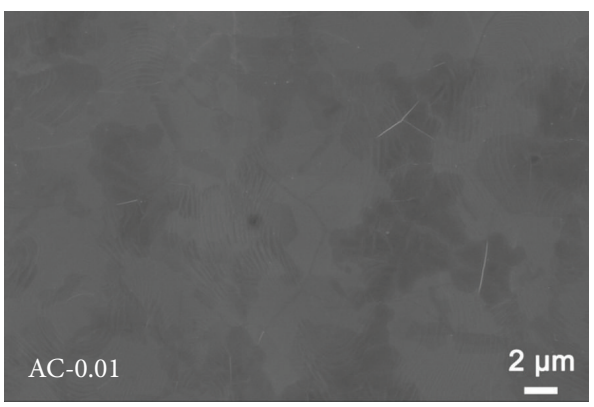

(a)

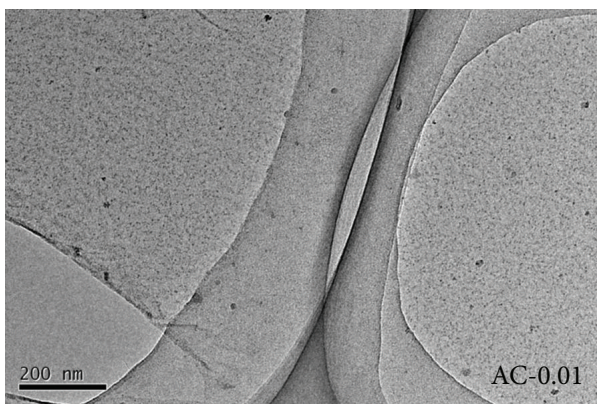

(c)

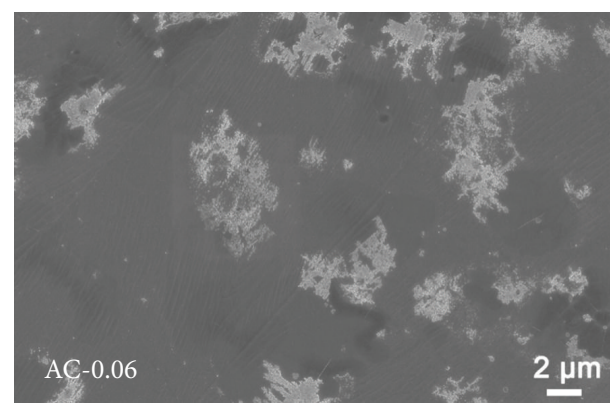

(b)

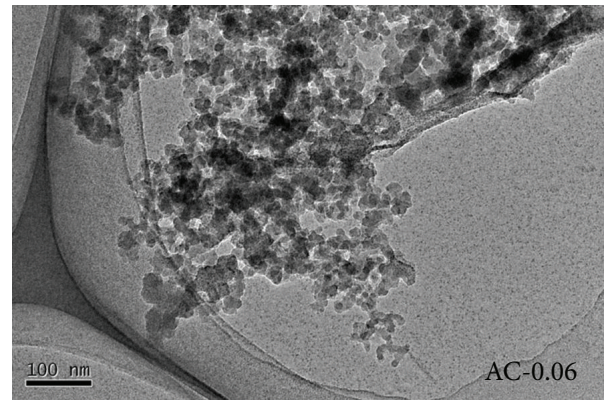

(d)

FIGURE 4: SEM and TEM images of AC-0.01 and AC-0.06. (a) SEM image of AC-0.01, (b) SEM image of AC-0.06, (c) TEM image of AC-0.01, and (d) TEM image of AC-0.06.

TABLE 1: Characteristics of G/Si solar cells based on different graphene samples before and after $\mathrm{HNO}_{3}$ treatment.

\begin{tabular}{|c|c|c|c|c|}
\hline Samples & $V_{\mathrm{oc}}(\mathrm{mV})$ & $J_{\mathrm{sc}}\left(\mathrm{mA} / \mathrm{cm}^{2}\right)$ & $\mathrm{FF}(\%)$ & $\eta(\%)$ \\
\hline AC-0.01-original & 472.4 & 15.57 & 30.78 & 2.26 \\
\hline $\mathrm{AC}-0.01-\mathrm{HNO}_{3}$ & 532.7 & 15.23 & 61.27 & 4.98 \\
\hline AC- 0.02 -original & 427.2 & 15.00 & 32.83 & 2.10 \\
\hline $\mathrm{AC}-0.02-\mathrm{HNO}_{3}$ & 487.5 & 15.99 & 53.75 & 4.19 \\
\hline AC-0.04-original & 427.2 & 12.07 & 19.69 & 1.02 \\
\hline $\mathrm{AC}-0.04-\mathrm{HNO}_{3}$ & 480.0 & 13.59 & 31.26 & 2.04 \\
\hline AC-0.06-original & 450.0 & 11.79 & 17.78 & 0.94 \\
\hline $\mathrm{AC}-0.06-\mathrm{HNO}_{3}$ & 502.6 & 15.56 & 22.28 & 1.74 \\
\hline
\end{tabular}

the curves that the quality of the Schottky junction is improved by $\mathrm{HNO}_{3}$ treatment. The diode ideality factor $(n)$ of the Schottky junction could be calculated by linear fit of $\ln (I)$ versus voltage, where $I$ is the dark current [31]. As shown in Figure 3(b), the $n$ has been improved from 3.82 (without $\mathrm{HNO}_{3}$ treatment) to 2.49 (upon $\mathrm{HNO}_{3}$ treatment) for AC-0.01 solar cell, demonstrating the improvement of the Schottky junction quality [32]. The $n$ for AC-0.02, AC0.04 , and AC-0.06 solar cells is improved by $\mathrm{HNO}_{3}$ treatment (Figure S2). In addition, a linear fit of $\mathrm{d} V / \mathrm{d}(\ln I)$ versus $I$ gives the $R_{s}$ of the Schottky junction [12]. As to AC-0.01 solar cell, the $R_{s}$ has dropped from $67.6 \Omega$ in the pristine cell to $51.1 \Omega$ in the $\mathrm{HNO}_{3}$-treated cell, as shown in Figures 3(c) and $3(\mathrm{~d})$. The $R_{s}$ for the other three cells is also reduced by $\mathrm{HNO}_{3}$ treatment (Figure S3). The improvement of the Schottky junction quality and the decrease of $R_{s}$ are beneficial to the improvement of FF, which can be seem from Table 1, where The FF of all the cells was enhanced by the $\mathrm{HNO}_{3}$ treatment.

From Table 1, we also obtain the evident and important result that solar cells based on AC- 0.01 and AC-0.02 demonstrate much better performance than those based on AC0.04 and AC-0.06. Furthermore, the efficiency improvement by $\mathrm{HNO}_{3}$ treatment of AC-0.01, AC-0.02, and AC-0.04 is superior compared with that of AC-0.06. The typical SEM images of AC- 0.01 and AC- 0.06 are shown in Figures 4(a) and 4(b). As one can see, the surface of AC-0.01 is almost free of impurities, while there are many agglomerates located on the surface of AC-0.06. TEM image further confirms the surface of AC-0.01 is very clean (Figure 4(c)); while the agglomerates on the surface of AC-0.06 are irregularly shaped particles (Figure 4(d)). The photovoltaic performance difference of the $\mathrm{G}$ films might be due to the irregularly shaped agglomerates.

As can be seen from Table 1, the photovoltaic performance difference between AC-0.04, AC-0.06 and AC-0.01, AC-0.02 mainly results from their difference in $J_{\mathrm{sc}}$ and $\mathrm{FF}$. The diode ideality factor of AC-0.02, AC-0.02- $\mathrm{HNO}_{3}, \mathrm{AC}-0.04, \mathrm{AC}-$ $0.04-\mathrm{HNO}_{3}, \mathrm{AC}-0.06$, and $\mathrm{AC}-0.02-\mathrm{HNO}_{3}$ is 3.87, 2.68, 4.12, 3.41, 4.57, and 3.69, respectively, as shown in Figure S3. The $R_{s}$ of AC-0.02, AC-0.02- $\mathrm{HNO}_{3}, \mathrm{AC}-0.04, \mathrm{AC}-0.04-\mathrm{HNO}_{3}$, $\mathrm{AC}-0.06$, and $\mathrm{AC}-0.06-\mathrm{HNO}_{3}$ is $70.6,57.2,82.9,63.2,136.6$, and $79.2 \Omega$, respectively, as shown in Figure S2. The diode ideality factor and $R_{s}$ of $\mathrm{AC}-0.04$ and $\mathrm{AC}-0.06$ are much poorer than these of AC-0.01 and AC-0.02, resulting in their lower FF. Our results are in agreement with previous report work that impurity on graphene surface results in poor diode behavior [33]. Graphene film also acts as a transparent 
electrode in our G/Si Schottky junction solar cells. As mentioned above, higher feed rate graphene samples show lower visible light transmittance and larger sheet resistance, which are supposed to be caused by the impurities on their surface. Moreover, reduced light absorption and poor sheet resistance are harmful for the generation and transport of charge carriers; thus, the $J_{\mathrm{sc}}$ of $\mathrm{AC}-0.04$ and $\mathrm{AC}-0.06$ is lower than that of AC-0.01 and AC-0.02. It is shown that agglomerates on graphene surface show a negative effect on graphene conductivity and the $R_{s}$ of G/Si solar cells, resulting in poor photovoltaic performance. Generally, optimization of the hydrocarbon precursor feed rate plays a vital role in photovoltaic application and improvement of graphene films.

\section{Conclusion}

In summary, effect of acetonitrile feed rate on the growth and photovoltaic performance of graphene films was investigated. Graphene/Si solar cells based on graphene films produced with feed rates of $0.01,0.02,0.04$, and $0.06 \mathrm{~mL} / \mathrm{min}$ demonstrate efficiencies of $2.26 \%, 2.10 \%, 1.02 \%$, and $0.94 \%$, respectively. The respective efficiencies increased to $4.98 \%$, $4.19 \%, 2.04 \%$, and $1.74 \%$ upon $\mathrm{HNO}_{3}$ treatment. The efficiency improvement by $\mathrm{HNO}_{3}$ treatment is mainly due to the increase of the graphene work function and the decrease of the internal resistance. Graphene samples synthesized with high feed rate show poor photovoltaic performance, due to the coexistence of many impurities on their surface, which show a negative effect on the diode ideality factor and the internal resistance of the Schottky junctions and thus lead to low filling factors. Our results indicate that controlling feed rate of hydrocarbon precursor is an effective way for tailoring the morphologies and photovoltaic properties of graphene, which will open up opportunities for facilitating their applications in many fields, such as energy conversion/storage devices, catalyst support, sensors.

\section{Conflict of Interests}

The authors declare that they have no conflict of interests regarding the publication of this paper.

\section{Acknowledgments}

The authors are grateful to the financial supports from the National Natural Science Foundation of China (Grant no. 51372131) and 973 program of China (no. 2014CB932401).

\section{References}

[1] A. K. Geim and K. S. Novoselov, "The rise of graphene," Nature Materials, vol. 6, no. 3, pp. 183-191, 2007.

[2] L. Ai and J. Jiang, "Removal of methylene blue from aqueous solution with self-assembled cylindrical graphene-carbon nanotube hybrid," Chemical Engineering Journal, vol. 192, pp. 156$163,2012$.

[3] Y. Wang, S. W. Tong, X. F. Xu, B. Ozyilmaz, and K. P. Loh, "Interface engineering of layer-by-layer stacked graphene anodes for high-performance organic solar cells," Advanced Materials, vol. 23, no. 13, pp. 1514-1518, 2011.

[4] X. S. Li, W. W. Cai, J. H. An et al., "Large-area synthesis of highquality and uniform graphene films on copper foils," Science, vol. 324, no. 5932, pp. 1312-1314, 2009.

[5] Y.-M. Lin, C. Dimitrakopoulos, K. A. Jenkins et al., "100-GHz transistors from wafer-scale epitaxial graphene," Science, vol. 327, no. 5966, p. 662, 2010.

[6] S. Ameen, M. S. Akhtar, H.-K. Seo, Y. S. Kim, and H. S. Shin, "Influence of $\mathrm{Sn}$ doping on $\mathrm{ZnO}$ nanostructures from nanoparticles to spindle shape and their photoelectrochemical properties for dye sensitized solar cells," Chemical Engineering Journal, vol. 187, pp. 351-356, 2012.

[7] D. S. Hecht, L. Hu, and G. Irvin, "Emerging transparent electrodes based on thin films of carbon nanotubes, graphene, and metallic nanostructures," Advanced Materials, vol. 23, no. 13, pp. 1482-1513, 2011.

[8] L. G. de Arco, Y. Zhang, C. W. Schlenker, K. Ryu, M. E. Thompson, and C. W. Zhou, "Continuous, highly flexible, and transparent graphene films by chemical vapor deposition for organic photovoltaics," ACS Nano, vol. 4, no. 5, pp. 2865-2873, 2010.

[9] X. Wang, L. Zhi, and K. Mullen, "Transparent, conductive graphene electrodes for dye-sensitized solar cells," Nano Letters, vol. 8, no. 1, pp. 323-327, 2008.

[10] M. Y. Yen, M. C. Hsiao, S. H. Liao et al., "Preparation of graphene/multi-walled carbon nanotube hybrid and its use as photoanodes of dye-sensitized solar cells," Carbon, vol. 49, no. 11, pp. 3597-3606, 2011.

[11] R. Bajpai, S. Roy, N. Kulshrestha, J. Rafiee, N. Koratkar, and D. S. Misra, "Graphene supported nickel nanoparticle as a viable replacement for platinum in dye sensitized solar cells," Nanoscale, vol. 4, no. 3, pp. 926-930, 2012.

[12] X. M. Li, H. W. Zhu, K. L. Wang et al., "Graphene-on-silicon schottky junction solar cells," Advanced Materials, vol. 22, no. 25, pp. 2743-2748, 2010.

[13] Y. Ye, Y. Dai, L. Dai et al., "High-performance single CdS nanowire (nanobelt) Schottky junction solar cells with Au/graphene Schottky electrodes," ACS Applied Materials \& Interfaces, vol. 2, no. 12, pp. 3406-3410, 2010.

[14] Y. Ye, L. Gan, L. Dai et al., "A simple and scalable graphene patterning method and its application in CdSe nanobelt/graphene Schottky junction solar cells," Nanoscale, vol. 3, no. 4, pp. 14771481, 2011.

[15] X. Miao, S. Tongay, M. K. Petterson et al., "High efficiency graphene solar cells by chemical doping," Nano Letters, vol. 12, no. 6, pp. 2745-2750, 2012.

[16] Y. Lin, X. Li, D. Xie et al., "Graphene/semiconductor heterojunction solar cells with modulated antireflection and graphene work function," Energy \& Environmental Science, vol. 6, no. 1, pp. 108-115, 2013.

[17] X. Li, D. Xie, H. Park et al., "Anomalous behaviors of graphene transparent conductors in graphene-silicon heterojunction solar cells," Advanced Energy Materials, vol. 3, no. 8, pp. 10291034, 2013.

[18] E. Shi, H. Li, L. Yang et al., "Colloidal antireflection coating improves graphene-silicon solar cells," Nano Letters, vol. 13, no. 4, pp. 1776-1781, 2013.

[19] T. Feng, D. Xie, Y. Lin et al., "Efficiency enhancement of graphene/silicon-pillar-array solar cells by $\mathrm{HNO}_{3}$ and PEDOTPSS," Nanoscale, vol. 4, no. 6, pp. 2130-2133, 2012. 
[20] X. Li, D. Xie, H. Park et al., "Ion doping of graphene for highefficiency heterojunction solar cells," Nanoscale, vol. 5, no. 5, pp. 1945-1948, 2013.

[21] G. Fan, L. Fan, Z. Li et al., "Hybrid effect of gas flow and light excitation in carbon/silicon Schottky solar cells," Journal of Materials Chemistry, vol. 22, no. 8, pp. 3330-3334, 2012.

[22] X. Bai, J. Q. Wei, Y. Jia et al., "The influence of gas absorption on the efficiency of carbon nanotube/Si solar cells," Applied Physics Letters, vol. 102, no. 14, Article ID 143105, 2013.

[23] K. Ihm, J. T. Lim, K. J. Lee et al., "Number of graphene layers as a modulator of the open-circuit voltage of graphene-based solar cell," Applied Physics Letters, vol. 97, no. 3, Article ID 032113, 2010.

[24] T. Cui, R. Lv, Z.-H. Huang et al., "Effect of feed rate on the production of nitrogen-doped graphene from liquid acetonitrile," Carbon, vol. 50, no. 10, pp. 3659-3665, 2012.

[25] M. Regmi, M. F. Chisholm, and G. Eres, "The effect of growth parameters on the intrinsic properties of large-area single layer graphene grown by chemical vapor deposition on Cu," Carbon, vol. 50, no. 1, pp. 134-141, 2012.

[26] W. Liu, H. Li, C. Xu, Y. Khatami, and K. Banerjee, "Synthesis of high-quality monolayer and bilayer graphene on copper using chemical vapor deposition," Carbon, vol. 49, no. 13, pp. 41224130, 2011.

[27] T. Cui, R. Lv, Z.-H. Huang et al., "Synthesis of nitrogen-doped carbon thin films and their applications in solar cells," Carbon, vol. 49, no. 15, pp. 5022-5028, 2011.

[28] Z. Li, H. Zhu, D. Xie et al., "Flame synthesis of few-layered graphene/graphite films," Chemical Communications, vol. 47, no. 12, pp. 3520-3522, 2011.

[29] T. Cui, R. Lv, Z.-H. Huang et al., "Low-temperature synthesis of multilayer graphene/amorphous carbon hybrid films and their potential application in solar cells," Nanoscale Research Letters, vol. 7, no. 1, article 453, 2012.

[30] S. Bae, H. Kim, Y. Lee et al., "Roll-to-roll production of 30-inch graphene films for transparent electrodes," Nature Nanotechnology, vol. 5, no. 8, pp. 574-578, 2010.

[31] Y. Jia, A. Y. Cao, X. Bai et al., "Achieving high efficiency siliconcarbon nanotube heterojunction solar cells by acid doping," Nano Letters, vol. 11, no. 5, pp. 1901-1905, 2011.

[32] M. Bashahu and P. Nkundabakura, "Review and tests of methods for the determination of the solar cell junction ideality factors," Solar Energy, vol. 81, no. 7, pp. 856-863, 2007.

[33] H. Park, P. R. Brown, V. Buloyic, and J. Kong, "Graphene as transparent conducting electrodes in organic photovoltaics: studies in graphene morphology, hole transporting layers, and counter electrodes," Nano Letters, vol. 12, no. 1, pp. 133-140, 2012. 

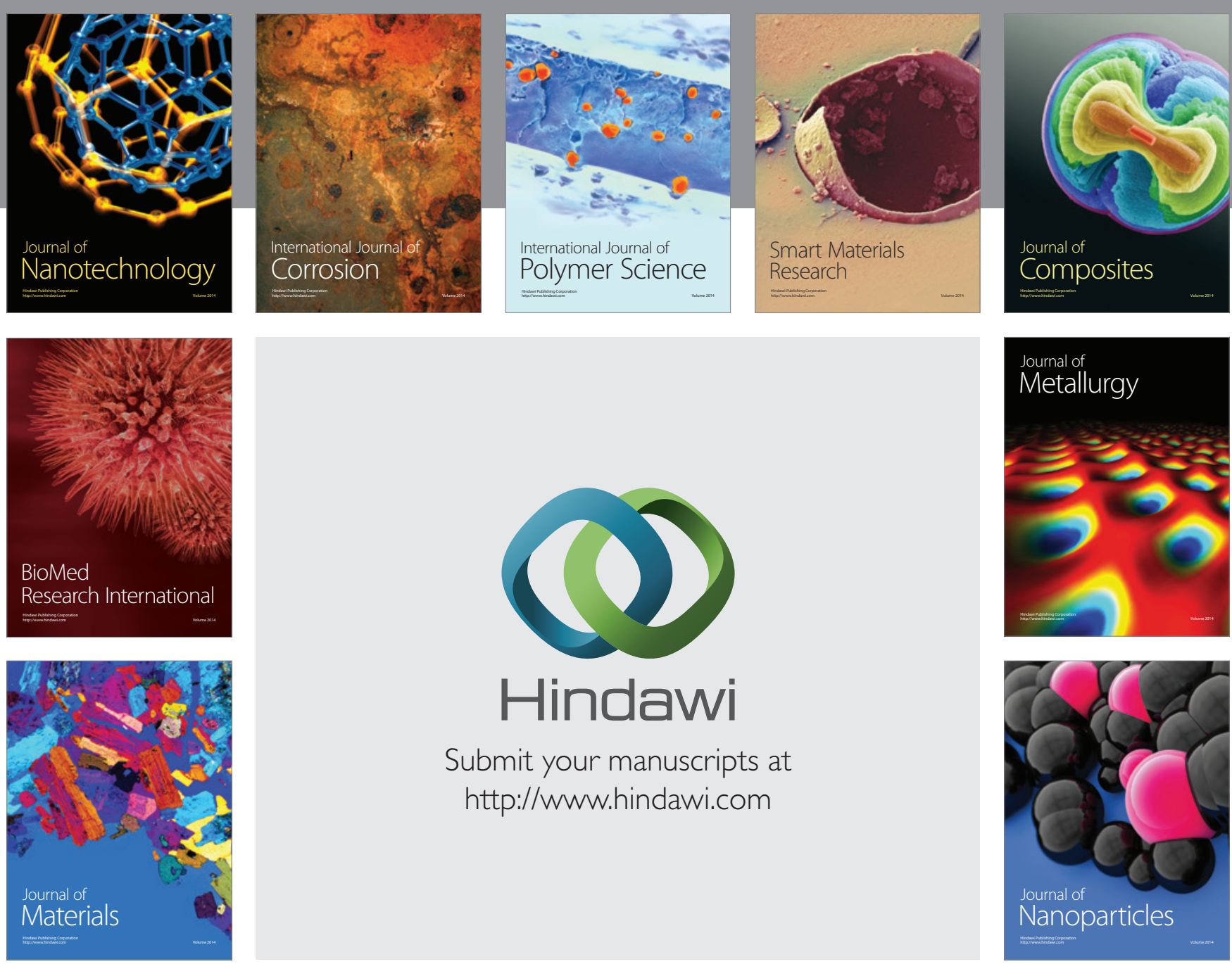

Submit your manuscripts at http://www.hindawi.com
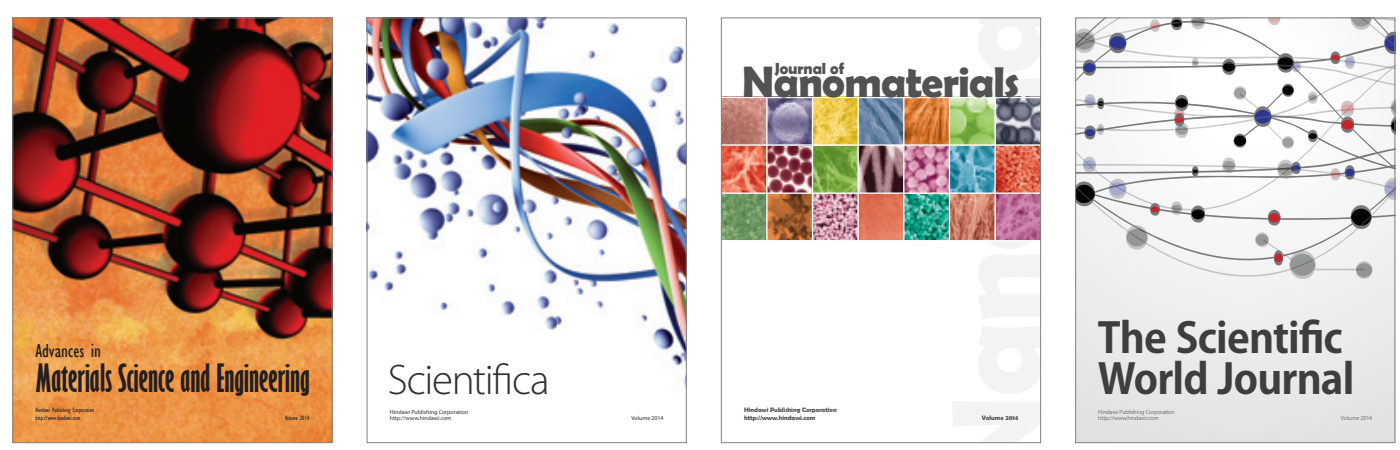

\section{The Scientific World Journal}
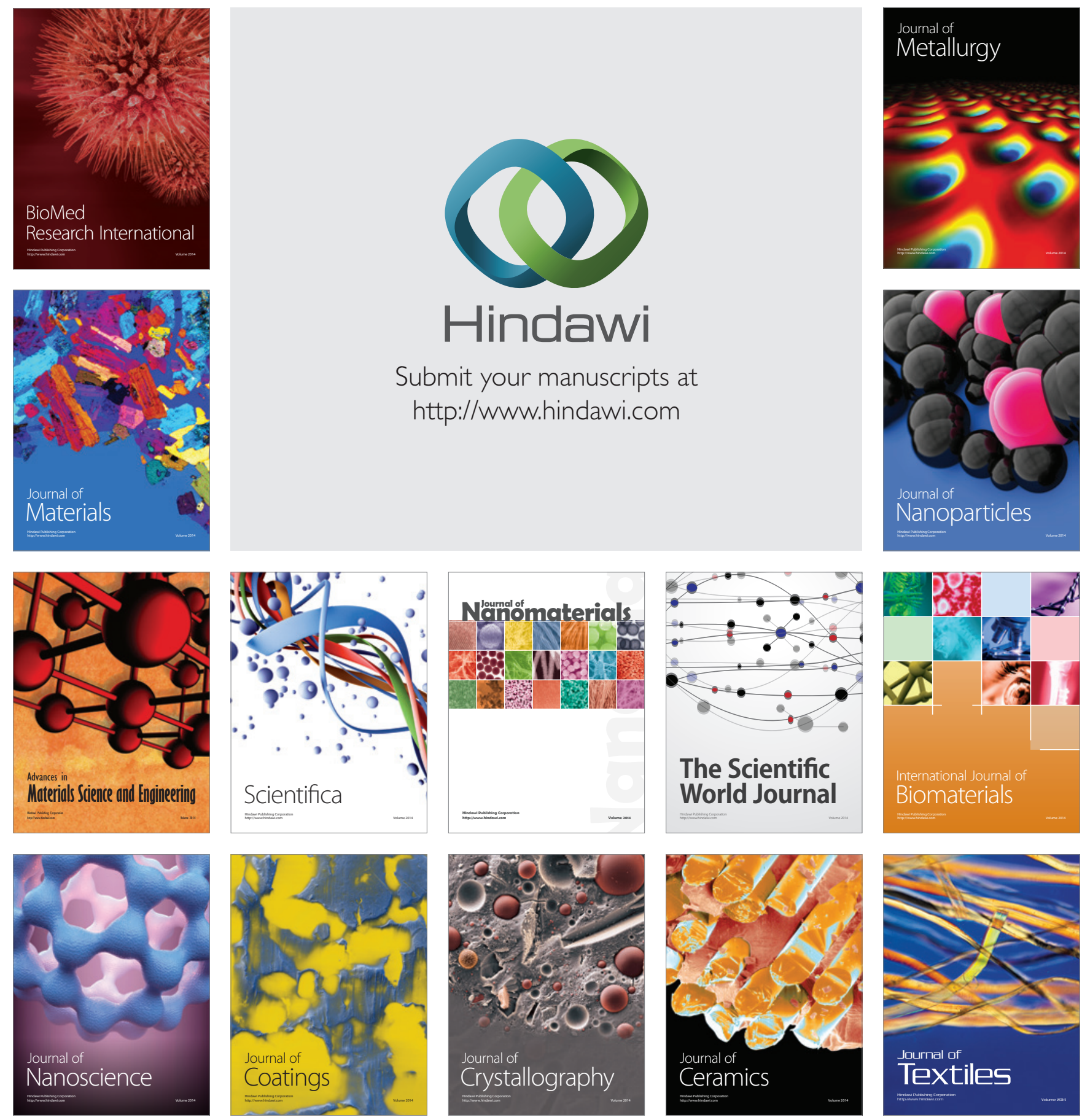